\title{
The usability evaluation of assistive technologies through qualitative research focusing on the people with mild dementia
}

\author{
Ikram Asghar ${ }^{a}$, Shuang Cang ${ }^{b}$, Hongnian $\mathrm{Yu}^{\mathrm{a}}$ \\ aFaculty of Science and Technology, Bournemouth University (BU), Fern Barrow, Talbot Campus, Poole, Dorset, BH12 \\ $5 B B, U K$ \\ bFaculty of Management, Bournemouth University (BU), Fern Barrow, Talbot Campus, Poole, Dorset, BH12 5BB, UK
}

\section{ABSTRACT}

The assistive technologies (ATs) are commonly used for the wellbeing of people with dementia (PWD). Research shows that current ATs are not performing to their best and high rate of AT abandonment still exist. Although empirical evaluations greatly impact AT success, yet only few studies investigated AT usability for PWD. To the best of authors knowledge there is no AT usability evaluation study conducted in the South Asia. Therefore a qualitative study is carried out to identify which AT factors encourage and discourage the PWD through semi-structured interviews. Thematic analysis is used to generate themes and sub-themes. The (happy users, non-happy users and technology and human care) emerged as three main themes while, (communication, monitoring and reminders) as popular AT types. Most PWD use ATs for socialization and health monitoring. Overall the PWD appreciated the role of ATs in their lives, but showed concerns about interface efficacy, function simplicity and elderly requirements adaptation. The already met and unmet needs of the PWD are also investigated. The AT producers should make user interface simpler and tailor future ATs to the specific requirements of the PWD. The user centred techniques should be adopted for the development of new ATs.

Keywords: Assistive technology, dementia, usability, evaluation, empirical investigation, semi-structured interviews

\section{Introduction}

From recent statistics it is evident that the world population is ageing. According to the United Nations survey, the world population aged 60 years or above stands at $11.7 \%$ (841 million people). This figure is expected to rise to $21.1 \%$ (2 billion people) by 2050 (Au, Lai, \& Ng, 2015). This ageing population is contributing significantly to the number of people with dementia (PWD) worldwide. Currently there are over 46.8 million PWD in the world (Pratchett, 2015). Interestingly this number is more than the individual population of 123 countries. Moreover the world is spending $\$ 818$ billion for betterment of the PWD every year. Again this investment is more than the annual GDP of 178 countries of the world (Pratchett, 2015).

Considering these giant social and economic impacts, the companies around the world are developing Assistive Technologies (ATs) for helping the PWD to live better lives. The ATs have potential to help the PWD to live independently (Tchalla, et al., 2012) (Boman, Lundberg, Starkhammar, \& Nygård, 2014). The literature highlights that the PWD offer unique challenges to the caregivers and family members (Fukuda, Shimizu, \& Seto, 2015). Still the family members prefer that the PWD should stay with them at home rather than at some care homes (Petrovic, 2013). The use of ATs can provide partial solutions like (cognitive or physical help) to these unique challenges due to the nature of dementia and can prolong the stay of the PWD at their own homes.

Currently the trend in academia for research regarding AT design and development for the PWD is on rise. The industry is transforming ideas into reality for the betterment and wellbeing of the PWD (Doukas, et al., 2011) (Imbeault, et al., 2014). Studies available in literature present new ideas and AT devices for the wellbeing of the PWD (Hoey, et al., 2010).

The fundamental goal for the technological industry' like all other businesses is to gain customer satisfaction by providing them with quality products (Asghar \& Usman, 2013). The AT usability evaluation studies can serve greatly in achieving this goal by highlighting the likes and dislikes of PWD for the existing ATs. Involving the PWD in such studies promotes their voice in academic research and serves as basis for requirements elicitation for the future ATs. It is strongly believed that technology success depends heavily on its end user perspectives. Therefore knowing the point of view of the PWD regarding the usability of existing ATs becomes more important (Scherer, 2005). Yet there are only few studies carried out in this domain (Span, Hettinga, Vernooij-Dassen, 
Eefsting, \& Smits, 2013). Such as (Rowe, et al., 2009) in USA, (Demers, Wessels, Weiss-Lambrou, Ska, \& De Witte, 2001) in Canada, (Jedeloo, Witte, Linssen, \& Schrijvers, 2002) in Netherlands and (Larsson Lund, Nygård, \& Kottorp, 2014) in Sweden have conducted some studies for testing AT usability from the users.

Recently in the South Asia, the researchers started to work on the wellbeing of the PWD and their caregivers (Ali \& Bokharey, 2015). The focus of these studies is on the care of the PWD through the caregivers and family members. To the best of the authors' knowledge, there are no AT usability evaluation studies conducted in the South Asian region with focus on the PWD. The importance of this study becomes even more significant as the South Asia holds 25\% of Worlds' population (Rasul, 2014). Delphi consensus study reports that there is an annual $1.9 \%$ increase in dementia population of the South Asia. According to a recent study statistics, the South Asia has over 4.5 million PWD (Prince, et al., 2013).

According to 2013 statistics, there are more than 150,000 PWD living in different parts of Pakistan and this population is increasing at a rate of $1.9 \%$ every year (Ahmad, et al., 2013). This steady rate of dementia population increase will create a challenge for already weak economy of Pakistan. Considering all these challenges, we therefore conducted this study in Pakistan by involving the PWD into productive talks and explored their point of view regarding the usability of current ATs and their future needs.

\subsection{Characteristics of people with mild dementia}

The dementia often causes gradual weakening of the memory and decline in some mental functions. Dementia grows rapidly for some people, whereas for others it may take years to go from initial to advance stage. At mild stage of dementia the people may perform some functions independently. Still, they will experience cognitive challenges that will affect their daily functioning, like forgetting things or words. The mild dementia include common symptoms like: changes in personality, forgetting recent events and weakening of memory, misplacing things and getting lost, challenges in collecting and stating thoughts and opinions, difficulty in solving complex tasks and difficulty in independent travel etc. (Reed-Guy, 2016).

\section{Literature review}

Researchers treat ATs as one of the best available solutions for the wellbeing of the PWD, which resultantly increased the production of ATs (Tchalla, et al., 2012) (Fardoun, Mashat, \& Ramirez Castillo, 2015). The manufacturers also claim that ATs are helping the PWD to live independently. However these claims can be validated by conducting empirical studies with the real subjects. Empirical studies are getting importance in recent years as these studies "are based on observed and measured phenomena and derive knowledge from actual experience rather than from theory or belief" (Cahoy). Due to scope of this study, this section highlights the empirical studies related to AT usability for the wellbeing of the PWD.

The opinion of 22 PWD relatives regarding AT support was investigated through questionnaires. The relatives showed positive opinion about the AT use for the wellbeing of the PWD (Engström, Lindqvist, Ljunggren, \& Carlsson, 2006). Another study investigated the staff members' satisfaction with AT usage for helping the PWD. This study also used questionnaires to collect data from 33 staff members. Data was collected before and six months after the implementation of AT support at the nursing home. The monitoring and reminders ATs were used for the test. The overall results showed that AT use significantly improved the staff members satisfaction with their work (Engström, Ljunggren, Lindqvist, \& Carlsson, 2005). A similar work investigated 14 staff members' perception of AT support through interviews before, during and after the implementation of ATs. At start staff members had diverse perceptions, but after the AT implementation most of the perceptions were on the positive side (Engström, Lindqvist, Ljunggren, \& Carlsson, 2009).

An automated reminder system was analyzed by involving eight PWD in 60 trials. the PWD completed more steps with the help of the reminders and reduced the number of interaction required between them and their caregivers (Labelle \& Mihailidis, 2006). Another study investigated the use of a reminder system in hand washing activity by involving six PWD. The PWD completed 11\% more steps independently and caregivers interactions also reduced by 60\% (Mihailidis, Boger, Craig, \& Hoey, 2008).

The comprehensive work in this field came from the Australian researchers who used a systematic review to identify empirical studies on AT use for the PWD. Their search identified 178 potentially relevant studies. The evaluation criteria excluded 142 studies, while remaining 32 studies received validity assessment using the approach from (Forbes, 1997). The results showed only eight studies as strongly, nine studies as moderately and 19 studies as weakly relevant. Further analysis showed that there was only little empirical evidence of supporting the PWD through ATs. The study concluded that there was still a high rate of AT nonacceptance as existing ATs were often unreliable and brought little difference to practical outcomes. They further emphasized on the need of better designed empirical studies based on large samples (Fleming \& Sum, 2014).

Although some AT usability empirical studies have been conducted recently, but their focused population is different (i.e. school children, people with disabilities, caregivers etc.), therefore researchers still believe that empirical studies focused on the PWD are ignored in literature (Span, et al., 2013) (Imbeault, et al., 2014). Moreover current ATs are not tailored to the needs of the PWD, which contribute to high rate of AT abandonment (Carrillo, Dishman, \& Plowman, 2009). 
Literature further suggests having direct interaction with the PWD to explore their requirements for the future ATs (Torrington, 2009) (Aloulou, et al., 2013) (McCabe \& Innes, 2013). The direct interaction will result into tailoring future ATs as per user requirements. The current study was initiated to fill these research gaps by empirically investigating AT advantages, limitations, functionalities and impacts on the PWD and exploring their future requirements. The objectives of this study are achieved by answers the following research questions.

RQ1: What are major ATs used by the PWD?

RQ2: Which factors encourage and discourage the PWD to use ATs?

RQ3: What are the requirements of the PWD for the future ATs?

\section{Methods}

Figure 1 summarizes the research process followed throughout the study. It includes (i) interviews template design and validation, (ii) survey participants, data collection and analysis and (iii) study context and ethical considerations.

\subsection{Interview template design and validation}

Previous studies show that focus groups and interviews are both popular methods for empirical studies which involve the PWD (Fukuda, et al., 2015) (Lykkeslet, Gjengedal, Skrondal, \& Storjord, 2014). As the target population for this study was dispersed in different cities of Pakistan, therefore we adopted the semi-structure interviews method in which "the interviewer sets up a general structure by deciding in advance the ground to be covered and the main questions to be asked", (Drever, 1995). This method gives the interviewers and interviewees a chance to explore issues they feel important in a structured way. This technique is famous for small scale research due to its flexibility.

The interview template design was a critical task as the outcome was dependent on the quality of the template. Guidelines for designing the semi-structured interview template were followed from (Jones, 2004). The questions required special attention as the targeted population was PWD, therefore the questions were designed based on the "Media guidelines for interviewing/meeting PWD" (Ireland, 2015). The structure of questions was made simple based on the recommendations by (Beuscher \& Grando, 2009b). The number of questions was kept limited as often the PWD cannot concentrate for longer periods and may refuse to answer the longer questions. The PWD may also require ample time for answering the questions; therefore a shorter template can serve the purpose better.

The semi-structured interview template had 15 questions and was adapted and modified from (MTN, 2014). The $1^{\text {st }}$ version of the template was evaluated by two academic experts, two Master's, two $\mathrm{PhD}$ and one Post DOC researchers. Based on their recommendations, minor changes were made and the $2^{\text {nd }}$ version was then tested with two PWD for accessing its easiness and validity. The PWD showed their satisfaction with the $2^{\text {nd }}$ version.

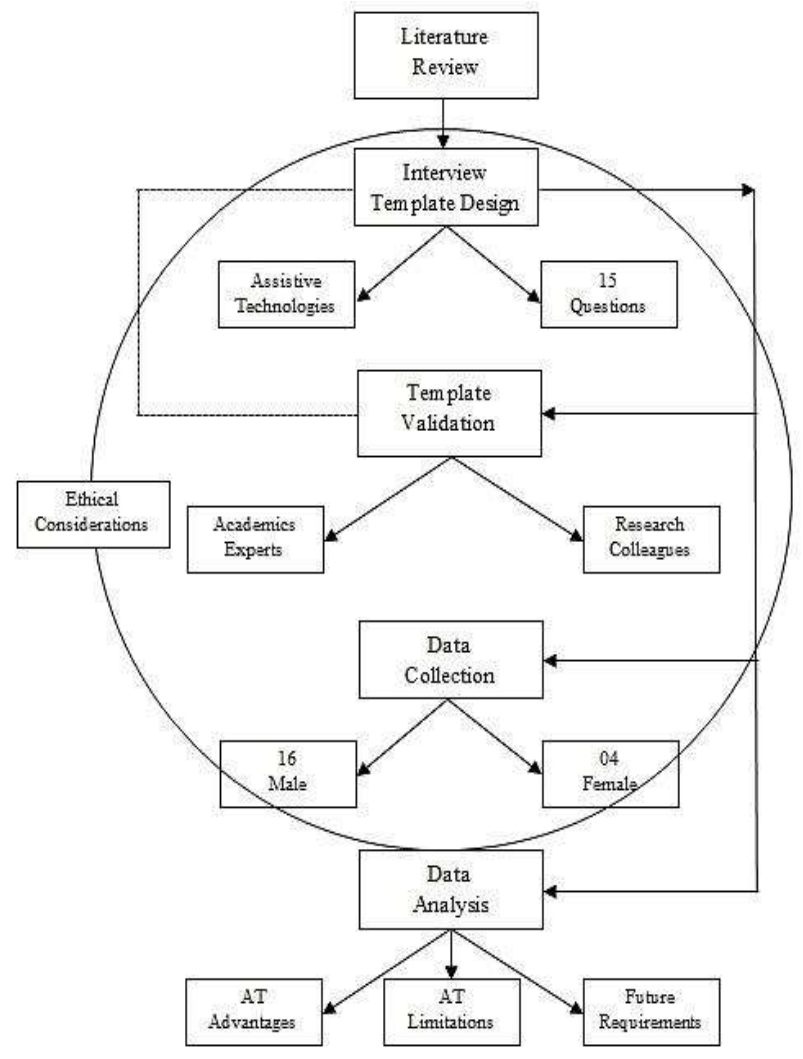

Fig. 1. Research process used for the study

\subsection{Survey Participants, data collection and analysis}

After design, development and validation of the template, data was collected by interviewing the PWD. The people with mild dementia scoring 20-25 with the Mini-Mental State Examination (MMSE) were contacted (Ahmad, et al., 2013). Although the researchers have different arguments on the number of interviews in qualitative research, yet there are no specific criteria regarding the number of interviews when PWD are involved in research as subjects. The existing studies involving PWD are usually based on 12 to 15 interviews (Mazaheri, Eriksson, Nasrabadi, Sunvisson, \& Heikkilä, 2014) (Beuscher \& Grando, 2009a).

Taking this into consideration, a number of requests were made for the PWD who can use ATs to volunteer for interviews. Initially 22 people showed their willingness to take part in this activity, but later on two refused due to some illness. In total 20 interviews were done with the participants (16 males, 4 females) from four major cities of Pakistan.

Their distribution was: six from Islamabad, three from Faisalabad, five from Lahore and six from Mianwali. 
For interviews based qualitative studies the thematic analysis is popularly used as it provides " a method for identifying, analyzing and reporting patterns within data". For this study the six steps thematic mapping analysis is applied by following Braun and Clarke guidelines (Braun \& Clarke, 2006)

As the $1^{\text {st }}$ step, the verbal data was transcribed. Each interview was interpreted by listening to the recordings to develop overall understanding. After documentation of the interviews, a cross validation was done by listening to recordings. The whole data was read twice and key notes for initial ideas were taken at this stage. At the $2^{\text {nd }}$ step the NVivo was used for initial data codes. The researchers tried to come up with as many candidate codes and themes as possible at this stage. After coding all the data, the data with the same codes was collated together. At the start of the $3^{\text {rd }}$ step, the researchers had a long list of different codes. After that the mind maps were used to sort different codes into potential themes. Most of the codes were kept which resulted into themes and sub-themes, the other codes were discarded. The $4^{\text {th }}$ step involved the refinement of themes. Two of the themes were collapsed into other themes, while one theme was fragmented in smaller components. The coherence of data extracts into each theme was tested. Additionally the relationships of the themes with each other were also checked through thematic mapping. At the $5^{\text {th }}$ step, the working titles of the themes and sub-themes were replaced by the official names. After many revisions of themes in relation to the collected data, the final thematic map was produced. As the $6^{\text {th }}$ and final step, the analysis was transcribed as report with sufficient evidence related to each theme and sub-theme was the interviews data and existing literature.

\subsection{Study context and ethical considerations}

The ethical approval for the study was taken from the research ethics committee of the Bournemouth University. Some care homes and medical professionals from Pakistan were also taken on board for this study. In order to establish connection with the researcher, the participants were presented traditional Pakistani sweets before the interviews. At the start of each interview, the interviewer sought willingness of the individuals and their family members as recommended by (Hellström, Nolan, Nordenfelt, \& Lundh, 2007). The interviewer also encouraged the PWD to tell any interesting stories while using ATs in their lives, as often these stories gives useful insights for topic under investigation (Ireland, 2015). The interviews were audio recorded with the prior permission of each participant. The interviews lasted for 25 to 30 minutes each. To avoid 'hit and run' impression the interviewer spent more time with each participant after finishing the interview and took tea or coffee with them so that the interest between them continue after the formal interview process (Clarke \& Keady, 2002).

\section{Results and discussion}

This study highlights the experiences of the PWD who use different ATs for performing their daily activities. Table 1 summarizes the profiling information of the survey participants. The main contribution came from 16 males and there were one four females, as accessing female participants in Pakistan is difficult due to culture and traditions. As the targeted population was people having mild dementia, resultantly all the participants were aged between 63 to 72 years (Mean $=68)$. The majority of the participants (17) lived at their own homes with their families as Pakistan signifies a collectivist society, while only (3) lived at care homes (Asghar \& Usman, 2013). The AT usage experiences of the participants ranged from one to five years $($ Mean $=2.7)$. Some participants were using more than one AT devices at the same time.

\subsection{Themes and sub-themes}

The thematic mapping analysis helped to distribute data into three major themes and six sub-themes (see table 2), which reveal the experiences of the PWD with ATs. The experiences reflect three spheres: the person in the society (public sphere), the person in the family (private sphere) and the person herself/himself (personal sphere). The themes comprise of: the happy users because of improved communication with others (public sphere); the non-happy users due to lack of privacy and social isolation (private sphere) and the user desired to have balance between technology and human care (personal sphere).

\subsection{Theme 1: The happy users}

In general most (13 out of 20) participants felt 'comfortable' using ATs for their daily functioning. While discussing the advantages and limitations of the ATs, the participants were mainly happy with the AT assistance. For them the critical challenge was related to functional difficulties that they have to face during daily activities and ATs were helping them to minimize these barriers. The ATU1 expressed his delight by saying:

"The ATs help me to do many activities easily and independently without depending on others. I can make one touch call by clicking on the pictures and go outside independently without any fear."

The happy users termed facilitated communication, travel and timely medication and activities support as major contributions of AT support in their lives. 
Table 1

Profiling information of the survey participants: (ATU) - AT User; (M) - Male; (F) - Female.

\begin{tabular}{cccccl}
\hline $\begin{array}{c}\text { Participant } \\
\text { Number }\end{array}$ & Gender & $\begin{array}{c}\text { Age } \\
\text { (Years) }\end{array}$ & Living Place & $\begin{array}{c}\text { AT Use Duration } \\
\text { (Years) }\end{array}$ & $\begin{array}{c}\text { AT Type } \\
\text { Used }\end{array}$ \\
\hline ATU 1 & M & 69 & Own Home & 3 & Communication \\
ATU 2 & M & 67 & Own Home & 2 & Reminders and Prompts, Communication \\
ATU 3 & F & 72 & Own Home & 4 & Communication \\
ATU 4 & M & 71 & Own Home & 2 & Health and Activity Monitoring \\
ATU 5 & M & 67 & Own Home & 3 & Communication \\
ATU 6 & M & 69 & Own Home & 1 & Health and Activity Monitoring \\
ATU 7 & F & 64 & Own Home & 2 & Health and Activity Monitoring \\
ATU 8 & M & 72 & Care Home & 4 & Communication \\
ATU 9 & $\mathrm{M}$ & 64 & Own Home & 4 & Communication \\
ATU 10 & $\mathrm{M}$ & 63 & Own Home & 1 & Health and Activity Monitoring \\
ATU 11 & $\mathrm{F}$ & 68 & Own Home & 2 & Communication \\
ATU 12 & $\mathrm{M}$ & 72 & Own Home & 4 & Health and Activity Monitoring, Communication \\
ATU 13 & $\mathrm{M}$ & 67 & Own Home & 3 & Communication \\
ATU 14 & $\mathrm{M}$ & 69 & Care Home & 5 & Health and Activity Monitoring, Communication \\
ATU 15 & $\mathrm{M}$ & 70 & Own Home & 3 & Communication \\
ATU 16 & $\mathrm{M}$ & 66 & Own Home & 2 & Health and Activity Monitoring, Communication \\
ATU 17 & $\mathrm{M}$ & 67 & Own Home & 3 & Health and Activity Monitoring \\
ATU 18 & $\mathrm{F}$ & 65 & Own Home & 2 & Health and Activity Monitoring \\
ATU 19 & $\mathrm{M}$ & 71 & Own Home & 3 & Communication \\
ATU 20 & $\mathrm{M}$ & 66 & Care Home & 2 & Reminders and Prompts \\
\hline
\end{tabular}

\subsubsection{Subtheme 1: Facilitated communication}

The communication support for the PWD is usually believed as critical for helping them. The literature also support this argument that the ATs have the potential to increase the number of communication opportunities for the PWD and decrease their loneliness (Meiland, et al., 2014). The survey participants had almost similar views regarding the communication help they were able to get through the support of ATs.

The ATU5 described that AT usage had decreased his loneliness and resulted into more frequent contacts by his friends to enquire about him. He pointed out that:

"I can talk easily to my family members and friends. In fact they themselves contact me every day".

In two similar talks the AUT8 and ATU19 praised socialization and one-touch facilities for communication through ATs by describing:

"I use Facebook and picture based calling on assistive mobile application which help me to be in contact with loved ones",

"I can use assistive applications on my smart phone for connecting others at single click".

Another important point came from ATU9 as he not only praised the communication assistance of ATs, but also highlighted that this assistance could also be used for medical purposes. He described this situation as:
"I use software application for contacting friends and doctors. I share my health details with the doctor who advices me regarding diet and medication".

Table 2

Themes and subthemes through qualitative content analysis

\begin{tabular}{ll}
\hline Themes & Subthemes \\
\hline \multirow{3}{*}{ The happy users } & Facilitated communication \\
& $\begin{array}{l}\text { Facilitated travel } \\
\text { Timely medication and activities }\end{array}$ \\
\hline The non-happy users & $\begin{array}{l}\text { Promote social isolation and aggression } \\
\text { Not tailored to the user needs }\end{array}$ \\
\hline $\begin{array}{l}\text { Technology and human } \\
\text { care }\end{array}$ & Special training needed \\
\hline
\end{tabular}

Based on the same concept the developers at Tunstall developed Triagemanager a software platform which shares real time information of the PWD to the doctors and nurses. It is useful for timely interventions at the time of need and improves the safety of the PWD (Tunstall, 2015).

\subsubsection{Subtheme 2: Facilitated travel}

Independent travel is often highlighted as another critical challenge for the PWD as they face constraints like physical mobility, cognition, weak memory and forgetfulness. Although most of the survey participants were concerned about their abilities to travel without the help of other people, yet some of them shared their positive experiences for the support of AT in travel. The ATU16 pointed out that:

"I was unable to go out at my own. Recently my family bought me a smart watch which guides me when I am outside home. It is great help". 
He further recommended other PWD to start using smart watches as well for independent travel.

Some participants like ATU12 termed the AT support during travel from one place to another as a life changing experience and expressed his feeling as:

"With the use of GPS watch, now I can wonder outside my home independently which was not possible before as I often forgot my way back".

The literature also indicates the importance and contribution of independent travel for the rehabilitation. The systems like the Opportunity Knocks support the PWD in using public transport. It uses context aware information and whenever user deviates from their selected plans it notify them and guide them the correct way to return home (Patterson, et al., 2004).

The use of ATS for travel is also evident in real life places these days. There are many advanced travel facilitated technologies available commercially and the disabled people are seen using smart walkers at markets and public places. From the survey participants the ATU17 also used such smart walker which helped him to travel independently and perform his daily activities. He described this situation as:

"My smart walker has GPS and navigation system which help me move independently from one place to another. I go for shopping and meeting friends. I really enjoy my smart ride which gives me lot of confidence".

A systematic literature review aggregated knowledge about the smart walkers available for the PWD and highlighted the importance of smart walkers. The smart walkers are cost effective solutions and can easily increase the self-confidence of the PWD (Martins, Santos, Frizera-Neto, \& Ceres, 2012).

\subsubsection{Subtheme 3: Timely medication and activities}

Dementia is often associated with forgetfulness which causes lot of challenges for the people experiencing it. The weakening cognition creates issues like forgetting to take medicine, performing activities on time, and remembering about their health conditions. The ATs can be useful to avoid such situations. The assistance of ATs in this regard is highly appreciated by the ATU2 who expressed himself as:

"The reminders help to do activities on time which otherwise I forgot most often. The main advantage of using reminders for me is to take medicine on prescribed time".

The literature supports this situation by going one step ahead through the use of context aware reminders. These reminders not only help the PWD in daily tasks but also manages conflicts between pre-defined plans and real time destructive activities (Du, Zhang, Musa, Mokhtari, \& Zhou, 2008).
The ATs like the HomePod designed by Medvivo help the PWD to monitor their physiological data for weight, blood glucose, blood pressure etc. at home. The medical information provided by such ATs can be transferred to a doctor for analysis as well (medvivo, 2015). The ATU4 termed smart watch for health analysis as the best gift he received due to its effectiveness:

"Previously we have to visit a doctor for health conditions check-ups but now the smart watch helps us to monitor blood pressure, body temperature, heart rate etc. at our own home".

The use of AT for medical purposes is also appreciated by the ATU7:

"I have blood pressure and diabetes issues which need continuous monitoring. My doctor son and grandchildren monitor my health conditions with the help of health monitoring device. It is light weight and I always carry it with $m e "$.

In two similar talks the ATU14 and ATU18 showed their satisfaction with the health monitoring devices that they used by describing:

"I am using a health monitoring device for few years and happy using it”,

"The health monitoring device keeps me updated throughout the day".

The most interesting views came from ATU20 who had memory issues. His daughter brought him the Smart Caregiver in which she can record the reminders in her own voice (Solutions, 2015). Her voice was perceived by the participant as she was always around him. He described this situation as:

"I had issues in remembering things, so my daughter bought me a device to manage my activities. The device prompts audio messages with the voice of my daughter. It gives me the feeling that she is always with me".

\subsection{Theme 2: The non-happy users}

During the interviews (four out of 20) participants also showed their unhappiness with the ATs. The unhappiness was mainly associated with the consequences of AT adaptation. The most-unhappy participant was ATU6, who described his angriness as:

"I do not like being monitored all the time and AT sometimes gives false notifications that I have fallen. Now my family believes that I am safe through this system and they spend less time with me. My friends and relatives have reduced their visits to me as well".

The existing literature also suggest that some PWD don't like to adopt ATs as they believe these do not fulfill their requirements, compromise their privacy and result into reduced social circle. 


\subsubsection{Subtheme 1: social isolation and aggression}

Social isolation is amongst the critical issues associated with the PWD. The literature also indicates that in some cases the PWD who use ATs feel more isolated than others. The similar concern was raised by the ATU10 as he described the situation as:

"Although the monitoring device helps my family to monitor my health conditions, but in fact now they are less worried about me and every day they go to their jobs. The amount of time spent with me has decreased since they bought this device".

The issue of social isolation was also raised by ATU6. Additionally the family members of ATU6 told the researcher that due to continuous dependence on AT, their father often becomes aggressive, which was not a problem before bringing ATs into his life.

\subsubsection{Subtheme 2: Not tailored to the user needs}

Another criticism about the current ATs is that often they are not tailored to the needs of the PWD. The similar concern was raised by the ATU 13 that current ATs are not tailored according to his needs rather they are more appropriate for the young people, He pointed out that:

"Although I can use ATs for contacting people, but frankly speaking these ATs are not made for me. They are made for the young people and have difficult functions. If they are tailored as per older people needs, they can be more fun and useful for me".

The ATU15 has similar concerns about the social websites that these are for the young people not for the older people like him:

"I have learnt to use social websites for spending my spare time. I am fond of communication, but often these websites are difficult to use".

The user further recommends the development of ATs that are tailored to the needs of the elderly in general and the PWD in particular.

\subsection{Theme 3: Technology and human care}

During our discussions with (three out of 20) participants we noticed that although some of them were happy by using ATs, but at the same time they had some concerns as well. They emphasized the need to create balance between the use of technology and human care. The ATU3 emphasized this point as:

"I only enjoy using the AT in the company of my grandchildren as they are very dear to me. It gives me much pleasure when my grandchildren give me more time as they are also fond of using my AT'”.

The literature also supports this argument that the use of technology in combination with balanced human care can yield better results for the wellbeing of the PWD.

\subsubsection{Subtheme 1: Special training needed}

Training regarding the use of AT is essential especially for the PWD as they are often not familiar with the use of modern technologies. The ATU11 emphasized this point as:

"I only use the communication application on my tablet to stay in touch to my children living abroad. The functions other than calling are difficult to learn. I would prefer to learn these functions from others, as it will give me chance to see them more often".

The interesting thing about this point of view is that the participant thought that the training from other people will also bring him the chance to spend some time with them. This will help them to remove their social isolation as well.

\section{5. AT scope and categorization}

Based on these characteristics of the mild dementia, this study offers insights into the usability of the current ATs based on the real life experiences of the PWD. The study further reveals that the PWD can discuss the uses of ATs and its impacts on their lives. Based on the findings of the interviews and the characteristics of the mild dementia, the ATs are categorized for further analysis. AT categorization helped to analyze the benefits and limitations of existing ATs and the requirements of the PWD for future ATs.

The existing literature shows that there are many types of ATs which provide different types of supports for the PWD. These ATs include: mobile multimedia technologies help the PWD to communicate with others (Donnelly, et al., 2010), prompt technologies generate reminders to let the PWD know about doing some activity (Seelye, Schmitter-Edgecombe, Das, \& Cook, 2012), leisure technologies help in enjoyment activities (Torrington, 2009) and automatic task assistance technologies help in the completion of tasks in right order (Peters, Hermann, Wachsmuth, \& Hoey, 2014). However, the scope of AT support for this study is limited to the ATs used by the survey participants. Based on the survey results, the ATs used by the participants are classified into three major categories: 1- communication, 2- monitoring and 3reminders.

\subsubsection{Communication}

The ATs for communication were used by 13 participants mainly for socialization and interaction with family and friends. The communication ATs used by the survey participants included different software applications installed on their smart phones, laptops, iPads and tablets etc.

The benefits for communication: One of the objectives of this study was to understand the advantages of ATs from the PWD point of view. Therefore during interviews the participants were asked about the benefits they gain through the use of ATs. These 
benefits refer to the nature of assistance provided by the ATs in performing their daily activities.

The survey results indicated that most participants used ATs for communication and social contacts. The ATs like software applications and communication websites helped them to stay connected to their loved ones. At the same time these ATs also support leisure activities like cognitive games and paintings, pictures as memories etc.

In literature the sense of being socially isolated from rest of the society is often highlighted as a critical challenge for the PWD (Boman, et al., 2014). The feeling of social isolation for the PWD is also evident from this study as well. The use of ATs for communication and socialization will help them to decrease their sense of social isolation (Meiland, et al., 2014). ATs supported leisure activities are also considered important for the rehabilitation of the PWD (Torrington, 2009). Therefore ATs support in these directions can be useful for the overall betterment of the PWD and they should be encouraged to use ATs for social contacts and leisure activities.

Challenges for communication: Another objective of the study was to highlight the challenges and limitations of current from the PWD point of view. For that the participants were encouraged to talk about different challenges faced the use of ATs in their daily activities.

As far as communication ATs are concerned, the participants pointed out the small size of texts and fonts used by these ATs as a challenge for them. The small text and font size made it hard to read instruction and act upon them. Easy to use interface is also recommended by several researchers as well (Aloulou, et al., 2013) (Seelye, et al., 2012).

For some participants the communication functionalities offered by the current ATs are rather difficult to use. They pointed out that current ATs and their functionalities are based on the needs of young people and their specific needs are not considered carefully. It is already well established fact that the needs of the PWD are different as compared to others, while current ATs are not tailored to the specific needs of elderly population in general and the PWD in particular (Cho \& Lee, 2016). Additionally, if the specific needs of the PWD are not tailored in ATs, then dependence on such ATs can promote aggression among them (Carrillo, et al., 2009). Therefore considering the socialization and leisure needs of the PWD during AT development can yield better results and positive impacts on their lives (Leung \& Lee, 2005).

\subsubsection{Monitoring}

The ATs for the monitoring purposes were used by nine participants. It included health reading devices, smart watches and activity monitoring systems.

The benefits for monitoring: Some participants used ATs for health monitoring purposes. These devices helped them to monitor their physical conditions like blood pressure, heartbeat rate, diabetes level etc. on regular basis. This continuous health monitoring helped them to adapt a healthier life style (Schikhof, Mulder, \& Choenni, 2010).

The smart watches also assisted users in travelling outside their homes through GPS functionalities. Furthermore, some smart watches can monitor persons' physical health conditions as well as generating alerts at detection of abnormal health conditions (McCabe \& Innes, 2013). The use of ATs for monitoring should be encouraged among the PWD as it will promote self-monitoring of their own health by themselves.

Challenges for monitoring: The volume and heavy weight of smart watches used by the participants made it difficult for them to carry these all the time. Sometimes the wearing and un-wearing health monitoring devices also proved rather disturbing. The negative impacts of bulky and heavy weight smart watches are evidenced in literature as well (Lyons, 2015). Therefore there is need of lightweight and small smart watches especially designed for the PWD.

Although the participants understood that monitoring systems were there for their safety, but they did not like being monitored all the time at home or outside as it affected their privacy. The privacy concerns related to monitoring are also raised by (Zhou, et al., 2009). The current health monitoring ATs just monitor health conditions, but do not offer intelligent recommendations based on the health conditions. Addition of intelligent recommendations can yield better results of AT use for the PWD.

\subsubsection{Reminders}

As PWD often faced cognitive challenges; two participants used ATs for reminders which helped them in their daily functioning.

The benefits for reminders: The reminders ATs helped the $P W D$ family members and caregivers to set reminders for the specified times to perform important tasks. These ATs were also capable of recording audio messages and can deliver these messages as prompts on the pre-specified times. Such ATs are considered useful especially for the PWD as they often face cognitive challenges (Boger, et al., 2006). The context aware ATs like HYCARE issue smart prompts and reminders based on the surrounding conditions of the PWD and can contribute to their safety and independence (Mihailidis \& Fernie, 2002) (Du, Zhang, Zhou, et al., 2008).

Challenges for reminders: The participants found learning the operations of reminders based ATs rather difficult and considered it as a challenge for getting proper benefits. The existing ATs require external support for setting reminders which is another limitation found in this study and literature as well (Martins, et al., 2012) (Agree, 2014). Furthermore 
the PWD often find the noise created by prompts as rather disturbing.

\subsection{Future requirements for ATs (the met and unmet needs of the PWD)}

At the end of each interview the participants were asked about their specific requirements for the future ATs, which can help the developers and producers of ATs. Later on these requirements were analyzed against the ATs available in literature and commercial markets to check whether these requirements have been already implemented or not.

Most participants anticipated more user friendly interfaces from the future ATs and also requested the AT producers to make simple and easy to use functionalities. Additionally the participants further recommended tailoring the future ATs to the elderly needs.

The participants using monitoring ATs advised that the future monitoring ATs should also provide smart recommendations when they detect some abnormal health conditions. These ATs can use red alerts for making the users aware of their critical health conditions. In addition to this the future ATs should speak the health readings for elderly people to be aware of their health conditions. The AT developers should use machine learning approaches and smart algorithms to achieve these functionalities. To the best knowledge of the authors, these requirements are yet to be implemented within the discipline of ATs for the PWD and require further efforts from academia and industry. Implementation of these requirements can greatly help the PWD towards selfmanagement of their health.

Bigger texts and larger fonts are recommended by some of the participants as these will help them in reading and following instructions easily. These requirements are partially implemented in ATs like Nourish Carer Dashboard (care,

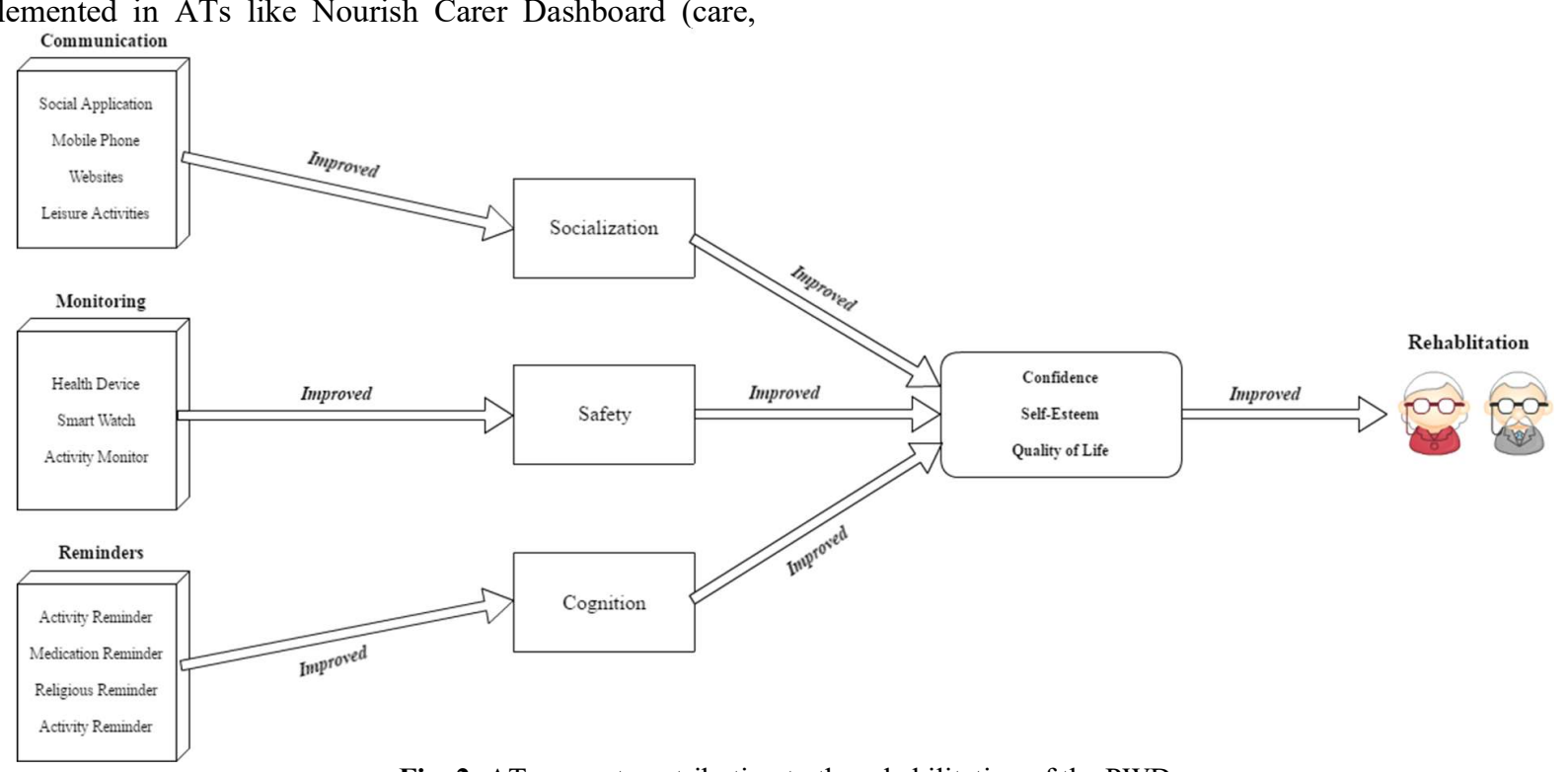

Fig. 2. AT support contributing to the rehabilitation of the PWD
2015) and True-Kare - revolutionary telecare service (TrueKare, 2015).

An interesting recommendation coming from the participants was related to the development of specialized games by focusing on needs of the PWD. These specialized games can help the PWD in learning activities and adopting healthy lifestyle. These recommendations are partially implemented as currently there are few games available for the PWD like Lumosity, Dakim, Clevermind, Fit Brain Trainers, Cognifit Brain Fitness, Brain Trainer, Brain Metrix and Eidetic etc. (Nouchi, et al., 2012) (Huntsman). Similarly the light weight smart watch recommendation is already fulfilled by (Bieber, Kirste, \& Urban, 2012).

Some participants further highlighted that religion becomes more important part of their life at older age and suggested the inclusion of prayer time and religious events reminders into the future ATs. The influence of religion factor effecting the PWD is also evident from (Heese, 2015). To the best of authors' knowledge, there is no work found in helping the religious activities through the use of ATs for the PWD. The development of ATs to support the religious can be a great contribution to existing body of knowledge and an excellent aid for the PWD.

Usually language understanding is also a barrier in accepting ATs; therefore the participants suggested the development of mobile applications in local languages like Urdu, Punjabi etc. The participants also advised to use the ATs in combination with human care as this combination can promote the wellbeing of the PWD. This recommendation is well supported in recent literature as it is believed that AT usage with balanced human contact can yield greater results (Asghar, Cang, \& Yu, 2017). Other functions like voice based calling and video based training on how to operate ATs by the device itself need attention of the future researchers as well. 


\subsection{The Impact of ATs for the PWD}

The main findings of this study and the relative impacts of ATs on the lives of the PWD are summarized in Figure 2. The communication ATs provide improved chances of socialization through social contacts and easier interactions with other people (Doukas, et al., 2011). The social interaction through ATs is considered as good as real care from the family members and caregivers (Mordoch, Osterreicher, Guse, Roger, \& Thompson, 2013). The monitoring ATs contribute to the improved safety of the PWD through decreased fear of loss and continuous monitoring of the health conditions (Meiland, et al., 2014). Finally the reminders assist in the improved cognition of the PWD through decreased memory and cognition barriers (Imbeault, et al., 2014).

The improved socialization, feeling of safety and enhanced cognition results into enhanced confidence and selfesteem of the PWD (Torrington, 2009). It is also evident in recent literature that these supports also contribute to the quality of life for the PWD (Leroi, et al., 2013) (Teipel, et al., 2016).

The combination of improved confidence, self-esteem and life quality motivate the PWD towards performing their daily functioning independently and contribute towards their rehabilitation (Martins, et al., 2012). In short ATs can be useful for prolonging the stay of the PWD at their own homes rather than relocating them to care homes and can save money for their families, care organizations and the Governments.

\subsection{Suggestions for AT producers}

The findings of this study have established that the PWD are able to use ATs for some of their daily activities. However, the PWD have few concerns which need attention for maximizing the usability of the ATs. The key highlights of this study including interface effectiveness, simple functions, tailoring elderly needs, technology and human care combination are consistent with the current literature as often these challenges are emphasized by other researchers as well (Boman, et al., 2014) (Aloulou, et al., 2013) (Mordoch, et al., 2013) (Seelye, et al., 2012).

The AT producers should accommodate the limitations identified in this study. It will help them in producing better quality ATs for the elderly in general and the PWD in particular. We recommend them to use to focus on user centered approaches for AT development by involving the PWD throughout the development process. It is believed that the involvement of real users will yield their real requirements and real requirements will result into better ATs (Qadir, Asghar, \& Ghayyur, 2009). The PWD can also contribute their views during the design and development of ATs.

Moving one step forward, the ATs should be tested through case studies by involving the PWD. These case studies will help to analyze the support and impacts of ATs on the daily activities of the PWD. These user centered approaches will help gaining better acceptability from the PWD along with producing effective ATs. The AT effectiveness will promote AT retention for longer period of time and ultimately the high rate of AT abandonment can be decreased.

\subsection{Study limitations}

One of the limitations for this study is that we were able to interview only 20 participants as the survey population was unique (the PWD who can use ATs). Additionally AT usage is not common among the older people in Pakistan, so only few older people use ATs for their daily functioning. The interviews were conducted in four major cities of Pakistan as accessing PWD who use ATs in small cities was a hard task. To generalize the results for South Asia, there is need for replicating this study in other countries of the South Asia with more number of participants.

\section{Conclusion and future work}

This study used semi-structured interviews for empirical analysis of the ATs used by the PWD. The interviews were conducted in central parts of Pakistan, as literature indicated there were no such studies performed in the South Asian region. Additionally the study explored first-hand information on the aspects that motivate AT use, limitations of existing ATs and future requirements of the PWD.

The results generated three major themes and six subthemes. The communication, monitoring and reminders emerged as popular AT types. Overall most of the participants were happy with the AT use and appreciated functionalities like reminders and prompts, socialization, health monitoring, independent travel, one touch calling etc. Still a few participants showed their concerns like AT adaptation resulting into social isolation, ATs not tailored to their specific needs, lack of privacy and dependence on others for AT functions.

The future ATs should focus on simplified user interfaces, addition of large fonts, simple functions and promotion of local languages. The interesting suggestions like inclusion of prayer time reminders and context aware health monitoring could be beneficial for AT acceptance and retention. The AT producers could overcome these limitations by adopting user centered development approaches.

Future researchers can also use questionnaires to collect similar data. It would be interesting to compare qualitative and quantitative results for better AT usability evaluation. The conduction of similar studies in other South Asian and Western countries has great potential as comparing such results will help to generate a global framework of AT acceptance for the PWD. 


\section{References}

Agree, E.M. (2014). The potential for technology to enhance independence for those aging with a disability. Disability and health journal, 7(1), S33-S39.

Ahmad, A., Owais, K., Siddiqui, M., Mamun, K., Rao, F., \& Yousufzai, A.W. (2013). Dementia in Pakistan: National Guidelines for Clinicians. PJNS, 8(3), 17-27.

Ali, S., \& Bokharey, I.Z. (2015). Maladaptive cognitions and physical health of the caregivers of dementia: An interpretative phenomenological analysis. International journal of qualitative studies on health and well-being, 10.

Aloulou, H., Mokhtari, M., Tiberghien, T., Biswas, J., Phua, C., Lin, J.H.K., \& Yap, P. (2013). Deployment of assistive living technology in a nursing home environment: methods and lessons learned. BMC medical informatics and decision making, 13(1), 42.

Asghar, I., Cang, S., \& Yu, H. (2017). Assistive technology for people with dementia: an overview and bibliometric study. Health Information \& Libraries Journal.

Asghar, I., \& Usman, M. (2013). Motivational and De-motivational Factors for Software Engineers: An Empirical Investigation. In Frontiers of Information Technology (FIT), 2013 11th International Conference on (pp. 66-71): IEEE.

Au, A., Lai, S., \& Ng, E. (2015). Introduction: Mental Health of Older Adults in Asia. Clinical Gerontologist, 38(3), 187189.

Beuscher, L., \& Grando, V.T. (2009a). Challenges in conducting qualitative research with individuals with dementia. Research in Gerontological nursing, 2(1), 6-11.

Beuscher, L., \& Grando, V.T. (2009b). Challenges in conducting qualitative research with persons with dementia. Research in Gerontological nursing, 2(1), 6.

Bieber, G., Kirste, T., \& Urban, B. (2012). Ambient interaction by smart watches. In Proceedings of the 5th International Conference on PErvasive Technologies Related to Assistive Environments (pp. 39): ACM.

Boger, J., Hoey, J., Poupart, P., Boutilier, C., Fernie, G., \& Mihailidis, A. (2006). A planning system based on Markov decision processes to guide people with dementia through activities of daily living. Information Technology in Biomedicine, IEEE Transactions on, 10(2), 323-333.

Boman, I.-L., Lundberg, S., Starkhammar, S., \& Nygård, L. (2014). Exploring the usability of a videophone mock-up for persons with dementia and their significant others. $B M C$ geriatrics, 14(1), 49.

Braun, V., \& Clarke, V. (2006). Using thematic analysis in psychology. Qualitative research in psychology, 3(2), 77 101.

Cahoy, E. Empirical Research in Education and the Behavioral/Social Sciences. In (Vol. 2015).

care, N. (2015). The human touch at the touch of a button. In (Vol. 2015).

Carrillo, M.C., Dishman, E., \& Plowman, T. (2009). Everyday technologies for Alzheimer's disease care: Research findings, directions, and challenges. Alzheimer's \& Dementia, 5(6), 479-488.

Cho, J., \& Lee, H.E. (2016). Contextualization of Motivations Determining the Continuance Intention to Use Smart Devices among People with Physical Disabilities. Telematics and Informatics.
Clarke, C., \& Keady, J. (2002). Getting down to brass tacks: A discussion of data collection with people with dementia. The perspectives of people with dementia: Research methods and motivations, 25-46.

Demers, L., Wessels, R., Weiss-Lambrou, R., Ska, B., \& De Witte, L.P. (2001). Key dimensions of client satisfaction with assistive technology: a cross-validation of a Canadian measure in The Netherlands. Journal of rehabilitation medicine, 33(4), 187-191.

Donnelly, M., Nugent, C., McClean, S., Scotney, B., Mason, S., Passmore, P., \& Craig, D. (2010). A mobile multimedia technology to aid those with Alzheimer's disease. IEEE multimedia, 2(17), 42-51.

Doukas, C., Metsis, V., Becker, E., Le, Z., Makedon, F., \& Maglogiannis, I. (2011). Digital cities of the future: Extending@ home assistive technologies for the elderly and the disabled. Telematics and Informatics, 28(3), 176190 .

Drever, E. (1995). Using Semi-Structured Interviews in Small-Scale Research. A Teacher's Guide: ERIC.

Du, K., Zhang, D., Musa, M.W., Mokhtari, M., \& Zhou, X. (2008). Handling activity conflicts in reminding system for elders with dementia. In 2008 Second International Conference on Future Generation Communication and Networking (Vol. 2, pp. 416-421): IEEE.

Du, K., Zhang, D., Zhou, X., Mokhtari, M., Hariz, M., \& Qin, W. (2008). HYCARE: A hybrid context-aware reminding framework for elders with mild dementia. Lecture Notes in Computer Science, 5120, 9-17.

Engström, M., Lindqvist, R., Ljunggren, B., \& Carlsson, M. (2006). Relatives' opinions of IT support, perceptions of irritations and life satisfaction in dementia care. Journal of telemedicine and telecare, 12(5), 246-250.

Engström, M., Lindqvist, R., Ljunggren, B., \& Carlsson, M. (2009). Staff members' perceptions of a ICT support package in dementia care during the process of implementation. Journal of nursing management, 17(7), 781-789.

Engström, M., Ljunggren, B., Lindqvist, R., \& Carlsson, M. (2005). Staff perceptions of job satisfaction and life situation before and 6 and 12 months after increased information technology support in dementia care. Journal of telemedicine and telecare, 11(6), 304-309.

Fardoun, H.M., Mashat, A.A., \& Ramirez Castillo, J. (2015). Recognition of familiar people with a mobile cloud architecture for Alzheimer patients. Disability and Rehabilitation, 1-5.

Fleming, R., \& Sum, S. (2014). Empirical studies on the effectiveness of assistive technology in the care of people with dementia: a systematic review. Journal of Assistive Technologies, 8(1), 14-34.

Forbes, D. (1997). Strategies for managing behavioural symptomatology associated with dementia of the Alzheimer type: a systematic overview. The Canadian journal of nursing research $=$ Revue canadienne de recherche en sciences infirmieres, 30(2), 67-86.

Fukuda, R., Shimizu, Y., \& Seto, N. (2015). Issues experienced while administering care to patients with dementia in acute care hospitals: A study based on focus group interviews. International journal of qualitative studies on health and well-being, 10.

Heese, K. (2015). Ageing, dementia and society-an epistemological perspective. SpringerPlus, 4(1), 135. 
Hellström, I., Nolan, M., Nordenfelt, L., \& Lundh, U. (2007). Ethical and methodological issues in interviewing persons with dementia. Nursing Ethics, 14(5), 608-619.

Hoey, J., Poupart, P., von Bertoldi, A., Craig, T., Boutilier, C., \& Mihailidis, A. (2010). Automated handwashing assistance for persons with dementia using video and a partially observable markov decision process. Computer Vision and Image Understanding, 114(5), 503-519.

Huntsman, M. 8 Brain-Training Games for Memory. In (Vol. 2015). Seattle Pacific University.

Imbeault, H., Bier, N., Pigot, H., Gagnon, L., Marcotte, N., Fulop, T., \& Giroux, S. (2014). Electronic organiser and Alzheimer's disease: Fact or fiction? Neuropsychological rehabilitation, 24(1), 71-100.

Ireland, A. (2015). Media Guidelines Interviewing/Meeting People with Dementia. In (Vol. 2015). Ireland: The Alzheimer Scoceity of Ireland.

Jedeloo, S., Witte, L.D., Linssen, B., \& Schrijvers, A. (2002). Client satisfaction with service delivery of assistive technology for outdoor mobility. Disability and Rehabilitation, 24(10), 550-557.

Jones, K. (2004). Enabling technologies for people with dementia. Report of the assessment study in England.

Labelle, K.-L., \& Mihailidis, A. (2006). The use of automated prompting to facilitate handwashing in persons with dementia. American Journal of Occupational Therapy, 60(4), 442-450.

Larsson Lund, M., Nygård, L., \& Kottorp, A. (2014). Perceived difficulty in the use of everyday technology: Relationships with everyday functioning in people with acquired brain injury with a special focus on returning to work. Disability and Rehabilitation, 36(19), 1618-1625.

Leroi, I., Woolham, J., Gathercole, R., Howard, R., Dunk, B., Fox, C., O'brien, J., Bateman, A., Poland, F., \& Bentham, P. (2013). Does telecare prolong community living in dementia? A study protocol for a pragmatic, randomised controlled trial. Trials, 14(1), 349.

Leung, L., \& Lee, P.S. (2005). Multiple determinants of life quality: The roles of Internet activities, use of new media, social support, and leisure activities. Telematics and Informatics, 22(3), 161-180.

Lykkeslet, E., Gjengedal, E., Skrondal, T., \& Storjord, M.-B. (2014). Sensory stimulation-A way of creating mutual relations in dementia care. International journal of qualitative studies on health and well-being, 9.

Lyons, K. (2015). What can a dumb watch teach a smartwatch?: Informing the design of smartwatches. In Proceedings of the 2015 ACM International Symposium on Wearable Computers (pp. 3-10): ACM.

Martins, M.M., Santos, C.P., Frizera-Neto, A., \& Ceres, R. (2012). Assistive mobility devices focusing on Smart Walkers: Classification and review. Robotics and Autonomous Systems, 60(4), 548-562.

Mazaheri, M., Eriksson, L.E., Nasrabadi, A.N., Sunvisson, H., \& Heikkilä, K. (2014). Experiences of dementia in a foreign country: qualitative content analysis of interviews with people with dementia. BMC public health, 14(1), 794.

McCabe, L., \& Innes, A. (2013). Supporting safe walking for people with dementia: User participation in the development of new technology. Gerontechnology, 12(1), 4-15.

medvivo. (2015). homepod. In (Vol. 2016): medvivo.
Meiland, F., Hattink, B., Overmars-Marx, T., De Boer, M., Jedlitschka, A., Ebben, P., Stalpers-Croeze, I.I., Flick, S., Van der Leeuw, J., \& Karkowski, I. (2014). Participation of end users in the design of assistive technology for people with mild to severe cognitive problems; the European Rosetta project. International Psychogeriatrics, 26(05), 769-779.

Mihailidis, A., Boger, J.N., Craig, T., \& Hoey, J. (2008). The $\mathrm{COACH}$ prompting system to assist older adults with dementia through handwashing: An efficacy study. $B M C$ Geriatr, 8(1), 1 .

Mihailidis, A., \& Fernie, G.R. (2002). Context-aware assistive devices for older adults with dementia. Gerontechnology, 2(2), 173-188

Mordoch, E., Osterreicher, A., Guse, L., Roger, K., \& Thompson, G. (2013). Use of social commitment robots in the care of elderly people with dementia: A literature review. Maturitas, 74(1), 14-20.

MTN. (2014). Interview Template. In (Vol. 2015).

Nouchi, R., Taki, Y., Takeuchi, H., Hashizume, H., Akitsuki, Y., Shigemune, Y., Sekiguchi, A., Kotozaki, Y., Tsukiura, T., \& Yomogida, Y. (2012). Brain training game improves executive functions and processing speed in the elderly: a randomized controlled trial.

Patterson, D.J., Liao, L., Gajos, K., Collier, M., Livic, N., Olson, K., Wang, S., Fox, D., \& Kautz, H. (2004). Opportunity knocks: A system to provide cognitive assistance with transportation services. In International Conference on Ubiquitous Computing (pp. 433-450): Springer.

Peters, C., Hermann, T., Wachsmuth, S., \& Hoey, J. (2014). Automatic Task Assistance for People with Cognitive Disabilities in Brushing Teeth-A User Study with the TEBRA System. ACM Transactions on Accessible Computing (TACCESS), 5(4), 10.

Petrovic, K. (2013). Respite and the Internet: Accessing care for older adults in the 21st Century. Computers in Human Behavior, 29(6), 2448-2452.

Pratchett, T. (2015). A global assessment of dementia, now and in the future. The Lancet Neurology, 14, 691.

Prince, M., Bryce, R., Albanese, E., Wimo, A., Ribeiro, W., \& Ferri, C.P. (2013). The global prevalence of dementia: a systematic review and metaanalysis. Alzheimer's \& Dementia, 9(1), 63-75. e62.

Qadir, M.M., Asghar, M.I., \& Ghayyur, S.A. (2009). Scaling of Critical success factors for Requirements engineering in the development of Large Scale Systems 1.

Rasul, G. (2014). Food, water, and energy security in South Asia: A nexus perspective from the Hindu Kush Himalayan region 访. Environmental Science \& Policy, 39, 35-48.

Reed-Guy, L. (2016). The Stages Of Dementia. In: Healthline.

Rowe, M.A., Kelly, A., Horne, C., Lane, S., Campbell, J., Lehman, B., Phipps, C., Keller, M., \& Benito, A.P. (2009). Reducing dangerous nighttime events in persons with dementia by using a nighttime monitoring system. Alzheimer's \& Dementia, 5(5), 419-426.

Scherer, M.J. (2005). Assessing the benefits of using assistive technologies and other supports for thinking, remembering and learning. Disability and Rehabilitation, 27(13), 731739.

Schikhof, Y., Mulder, I., \& Choenni, S. (2010). Who will watch (over) me? Humane monitoring in dementia care. 
International Journal of Human-Computer Studies, 68(6), 410-422.

Seelye, A.M., Schmitter-Edgecombe, M., Das, B., \& Cook, D.J. (2012). Application of cognitive rehabilitation theory to the development of smart prompting technologies. Biomedical Engineering, IEEE Reviews in, 5, 29-44.

Solutions, T.S. (2015). Smart Caregiver. In (Vol. 2016).

Span, M., Hettinga, M., Vernooij-Dassen, M., Eefsting, J., \& Smits, C. (2013). Involving people with dementia in the development of supportive IT applications: A systematic review. Ageing research reviews, 12(2), 535-551.

Tchalla, A.E., Lachal, F., Cardinaud, N., Saulnier, I., Bhalla, D., Roquejoffre, A., Rialle, V., Preux, P.-M., \& Dantoine, T. (2012). Efficacy of simple home-based technologies combined with a monitoring assistive center in decreasing falls in a frail elderly population (results of the Esoppe study). Archives of gerontology and geriatrics, 55(3), 683689.

Teipel, S., Babiloni, C., Hoey, J., Kaye, J., Kirste, T., \& Burmeister, O.K. (2016). Information and communication technology solutions for outdoor navigation in dementia. Alzheimer's \& Dementia, 12(6), 695-707.

Torrington, J. (2009). The design of technology and environments to support enjoyable activity for people with dementia. ALTER-European Journal of Disability Research/Revue Européenne de Recherche sur le Handicap, 3(2), 123-137.

True-Kare. (2015). True-Kare - Revolutionary Telecare Service. In (Vol. 2015).

Tunstall. (2015). Triagemanager. In (Vol. 2016).

Zhou, Z., Dai, W., Eggert, J., Giger, J.T., Keller, J., Rantz, M., \& He, Z. (2009). A real-time system for in-home activity monitoring of elders. In Engineering in Medicine and Biology Society, 2009. EMBC 2009. Annual International Conference of the IEEE (pp. 6115-6118): IEEE. 